\title{
Chemical cues and genetic divergence in insects on plants: conceptual cross pollination between mutualistic and antagonistic systems
}

\author{
by Segar, S.T., Volf, M., Sisol, M., Pardikes, N.A. and \\ Souto-Vilaros, D.
}

Copyright, Publisher and Additional Information: This is the author accepted manuscript. The final published version (version of record) is available online via Elsevier.

This version is made available under the CC-BY-ND-NC licence:

https://creativecommons.org/licenses/by-nc-nd/4.0/legalcode

Please refer to any applicable terms of use of the publisher

DOI: https://doi.org/10.1016/j.cois.2018.11.009

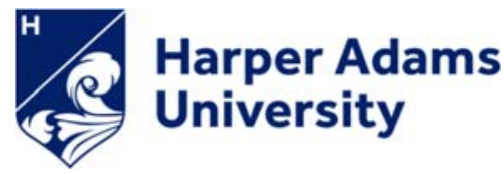

Segar, S.T., Volf, M., Sisol, M., Pardikes, N.A. and Souto-Vilaros, D. 2018. Chemical cues and genetic divergence in insects on plants: conceptual cross pollination between mutualistic and antagonistic systems. Current Opinion in Insect Science. 


\section{Accepted Manuscript}

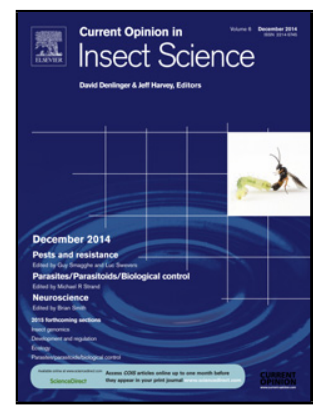

Title: Chemical cues and genetic divergence in insects on plants: conceptual cross pollination between mutualistic and antagonistic systems

Authors: Simon T. Segar, Martin Volf, Mentap Sisol, Nicholas A. Pardikes, Daniel Souto-Vilarós

PII: S2214-5745(18)30117-2

DOI: https://doi.org/10.1016/j.cois.2018.11.009

Reference: COIS 539

To appear in:

Please cite this article as: Segar ST, Volf M, Sisol M, Pardikes NA, Souto-Vilarós D, Chemical cues and genetic divergence in insects on plants: conceptual cross pollination between mutualistic and antagonistic systems, Current Opinion in Insect Science (2018), https://doi.org/10.1016/j.cois.2018.11.009

This is a PDF file of an unedited manuscript that has been accepted for publication. As a service to our customers we are providing this early version of the manuscript. The manuscript will undergo copyediting, typesetting, and review of the resulting proof before it is published in its final form. Please note that during the production process errors may be discovered which could affect the content, and all legal disclaimers that apply to the journal pertain. 
Special issue title: Communication in multitrophic interactions - new analytical approaches and emerging ecological consequences

Chemical cues and genetic divergence in insects on plants: conceptual cross pollination between mutualistic and antagonistic systems

Simon T. Segar ${ }^{1,2,3}$, Martin Volf ${ }^{4}$, Mentap Sisol ${ }^{5}$, Nicholas A. Pardikes ${ }^{1}$ and Daniel SoutoVilarós ${ }^{1,2}$

${ }^{1}$ Biology Centre, Czech Academy of Sciences, Ceske Budejovice, Czech Republic,

${ }^{2}$ Faculty of Science, University of South Bohemia, Ceske Budejovice, Czech Republic

${ }^{3}$ Department of Crop and Environment Sciences, Harper Adams University, UK

${ }^{4}$ Molecular Interaction Ecology Group, German Centre for Integrative Biodiversity Research (iDiv) Halle-Jena-Leipzig, Leipzig, Germany

${ }^{5}$ New Guinea Binatang Research Centre, Madang, Papua New Guinea

ORCID identifiers:

STS: 0000-0001-6621-9409

MV: 0000-0003-4126-3897

NAP: 0000-0002-9175-4494

DSV: 0000-0002-8803-5173

*Corresponding Author: simon.t.segar@gmail.com

\section{Highlights}

- Both herbivores and pollinators can act as selective agents for chemical and genetic variation in plants.

- We should study all three sets of organisms simultaneously in diverse and well replicated natural systems.

- We illustrate an example of this approach using the tropical plant genus Ficus. 


\begin{abstract}
Cascading or reciprocal genetic diversification of herbivores, parasitoids, and pollinators can track chemotypic variation in host resources, and can lead to non-overlapping communities. Because plants simultaneously interact with both pollinators and herbivores, models investigating the genetic divergence of antagonistic herbivores and mutualistic pollinators should be merged in order to study how both processes interact using a common conceptual and methodological approach. We expect insects to mediate divergence in many systems, with outcomes depending on the level of pollinator or herbivore specialization, and the relative selective pressures they impose. Applying approaches widely used to study insect pollinators, e.g. genomic tools and integration of behavioural, genetic and chemical data, to both pollinators and herbivores in the same system will facilitate our understanding of patterns of genetic divergence across multiple interacting species.
\end{abstract}

Key words: diversification, genomics, herbivory, pollination, speciation

\title{
Introduction
}

Both the reciprocal and cascading nature of diversification has long fascinated biologists. Two dominant biotic interactions driving insect and plant megadiversity are herbivory and pollination. The third trophic level, especially parasitoids, can further generate divergence in herbivores, through creating variation in enemy free space [1]. A central theme in the diversification of plants, herbivores, parasitoids and pollinators is chemical communication. Chemotypic variation can restrict gene flow and mediate the genetic structure of populations. Typically there has been a strong focus on reciprocal adaptation in plants and either their pollinators [2] or herbivores separately [3,4]. However, our understanding of how chemical communication among plants and insects contributes to genetic diversification in plants, pollinators, and herbivores simultaneously is limited. For example, herbivore-imposed selection may promote intra-specific chemical diversity among host plants, which can lead to subsequent sorting of herbivorous insects across chemically similar plants (e.g. through ecological fitting [5]) and assortative mating based on host preference. Even low levels of pleiotropy between leaf and flower chemistry can reinforce pollinator-mediated gene flow [6-9]. Antagonistic (e.g. plant defence) and mutualistic traits (e.g. flower volatiles) can be correlated [12], which may constrain the evolution of either [13]. Variable herbivore resistance to parasitoids across chemotypes may further cause specialisation of herbivores, through apparent competition [1]. All of these examples suggest that different interaction types do not operate in isolation, thus their linkages are likely to have significant consequences for patterns of genetic divergence across multiple, simultaneously interacting species.

Here we focus on intra-specific genetic and chemical variation and the formation of incipient species through limitations to gene flow among populations associated with different plant chemotypes. Our main aim is to use evolutionary models to put forward hypotheses relating to insect and plant genetic divergence along a continuum determined by the relative strength 
of biotic selection by herbivores and pollinators. Specifically, we focus on situations when both pollinators and herbivores can lead to different patterns of genetic divergence. A secondary aim is to discuss the rapidly developing methods required to address these hypotheses.

\section{Chemical variation and cues used by herbivores and parasitoids}

Genotypic differences among conspecific plants can predict the wider structure of insect communities [19]. Researchers have long recognised the ability of varietal types to confer different levels of resistance to insect herbivores and/or attraction to natural enemies. Furthermore, chemotypes appear to correspond well to taxonomic entities, genotypes and environments [20,21]. This variation forms the basis for the specialisation of insect herbivores within plant populations. Chemically-mediated recognition has long been known to modulate interactions throughout the life cycle of herbivorous insects [10].

Intra-specific variation in plants influences multiple trophic levels. We now recognise 'sequential divergence', which involves host associated genetic differentiation [1] within a single species (typically at the resource level) that can directly cause population level differentiation at higher trophic levels $[11,12]$, as an important eco-evolutionary process. Intra-specific divergence at the lower trophic levels is instrumental in opening up new niche space that is tightly linked to a specific resource. Herbivore host race association has long been accepted as a prime example of ecological speciation with potential for cascading effects [13]. Eventually, limitations to gene flow, mediated by host use, can promote host race formation and speciation, leading to macroevolutionary processes such as 'escape-andradiate' speciation [14] and 'oscillating radiation' [15]. Where herbivore-imposed selection is a major driver of chemotypic diversity across host plant individuals and populations (be it attractive volatile cues or defensive compounds), dynamics can be somewhat reciprocal. Divergence in plant chemistry can drive separation in herbivore host races and vice versa. Chemical divergence is one potential mechanism that can influence the population genetic structure of herbivores (Figure 1A shows a bimodal distribution of a hypothetical plant defence and corresponding host preference in herbivores). This is because population structure within a plant species can be generated through interactions with herbivores. Here, we expect selection to act against intermediate plant chemotypes because the major determinant of plant fitness will be survival to reproductive age and reproduction in the face of specialist herbivores that can cause significant levels of damage to plants (Fig. 1A). This is likely to support chemical divergence among plant hosts, which can prevent sharing such herbivores.

Some of the best evidence for sequential divergence stems from patterns of speciation in the parasitoids of the Hawthorn fly, Rhagoletis pomonella (Diptera, Tephritidae), species complex [12]. Speciation of hawthorn flies was driven by a scent preference for apples, instead of hawthorn fruits, and was followed by the divergence of hawthorn parasitoids. These authors [12] combined population genetic data with olfactometry to demonstrate hostassociated genetic divergence and preferences in parasitoids that corresponded to host race formation in flies. In this case, rapid ecological divergence appears to be preceded and facilitated by genetically or environmentally determined chemical diversity in insect cues: thus chemical diversity begets genotypic diversity which begets species diversity. 
A prerequisite for sequential divergence is that host-plant genotypes possess specific chemical signatures capable of acting as reliable oviposition cues for herbivore females. In the case of Cydia splendana (Lepidoptera, Tortricidae), sex pheromones are host-plant specific [16], leading to assortative mating. Furthermore, plant volatiles can signal appropriate oviposition sites [17] and interact with herbivore sex pheromones to mediate reproduction [18], this is especially relevant for herbivores mating on their hosts. In some cases, both plant volatiles of the undamaged host plant and adult sex pheromones are needed, which further links mate selection and oviposition cues and provides a mechanism for strengthening assortative mating and ecological divergence of herbivores across plant species $[19,20]$.

How do parasitoids and hyper-parasitods fit within this framework of tight and context dependent chemical signalling? Host location by parasitoids is a well-studied area, and we know that both host [21] and plant induced [22] volatiles are important. Parasitoids are also able to distinguish between closely related host herbivore species. For example, parasitoids can use cues experienced in larval stages to find oviposition sites later in life [23], further connecting larval experience to adult behaviour. Therefore, a continuous chain exists along which chemical information can travel, linking host herbivore chemistry to parasitoid behaviour. Chemical cues can be under strong directional selection and function as proximate cues for host choice. This strong linkage between host-plant chemistry and oviposition cues can ultimately lead to assortative mating and host race formation within parasitoids [24,25]. Parasitoids can diversify and specialise on host races or may even be agents of herbivore diversification themselves by facilitating hosts shifts towards enemy free space.

\section{Pollinator mediated divergence in plants, herbivores, and parasitoids}

Increased phytotoxicity, in response to strong herbivory, can also influence pollinator behaviour and provide a direct link to the genetic divergence of pollinator populations (one pathway to the outcome illustrated in Figure 1A). For example, the hemiparasitic plant Castilleja indivisa (Orobanchaceae) acquires alkaloids from its hosts, which increases pollinator visitation rates [26]. It is feasible that changes in defensive compounds shape the composition of nectar or volatile cues and determine pollinator preference [27], along with the strength and direction of gene flow (Figure 1A).

The process of herbivore driven genetic divergence is analogous to pollinator specialisation in angiosperms, for which chemical cues mediate reproductive isolation (Figure 1C). The parallel model is that intra-specific variation in floral cues can lead to sub-sets of plant individuals being pollinated by non-overlapping insect taxa. Further development of pollinator preference in specialised systems, combined with local adaptation of plants and limited pollinator dispersal, can lead to population genetic divergence in plants and pollinators. We expect this model to govern when plant fitness is pollination-limited. In herbivore/parasitoid and pollinator models, the initial variation in plant chemistry is key. Dynamics supporting variation in plant chemistry and pollinator host races can be reciprocal and this largely depends on the level of plant-pollinator specificity.

The pollination literature is rich with examples of chemically-mediated divergence, which are relevant to insect herbivores and their parasitoids. Generally, in angiosperms the more specific the pollination syndrome, the more species-rich the plant lineage [28]. One can draw further on concepts and methods developed to study speciation in pollinators and extend 
these to trophic interactions. For example, Whitehead and Peakall [29] outline a set of six hypotheses central to pollinator Genetic divergence. The first three suggest i) that pollinator specificity is mediated by volatile floral cues, ii) that these distinct cues predict species boundaries iii) hybridization occurs when volatile cues are similar. Their integrative framework combines behavioural, genetic, and chemical data to establish whether pollinating insects are i) attracted to certain hosts, ii) if the hosts themselves can be reliably identified, and iii) how this segregation of pollinators across plants determines population genetic structure. However, this framework ignores herbivores, which can alter behavioural, genetic, and chemical phenotypes of the plant and pollinator.

\section{Interactions between herbivores and pollinators on the same plant}

Divergence in floral volatiles can allow recruitment of specialized pollinators and strongly disrupt gene flow (Fig. 1C). Eventually, this could cascade to herbivores, as the leaf defences in separated host populations can evolve independently. We predict that reproductive isolation between plants and/or herbivores will be harder to achieve in the face of ongoing gene flow through pollination, unless there is pleiotropy between the genes determining chemical defence and pollination, as is the case in Nicotiana (Solanaceae) [30], or if intermediate chemotypes and hybrids suffer from extreme outbreeding depression. However, depending on the specific composition and specialization of the herbivore community, this can also lead to directional selection towards increase (escalation) or decrease (de-escalation) in chemical defences [31-33].

Few studies address the consequences of correlations between floral and defensive traits [34] at the species [35] and network levels [36]. For example, small genetic changes not only influence visitation by the principal pollinators, but also can deter unwanted visitors. In the case of Nicotiana attenuata, RNA interference in two loci blocks the production of benzyl acetone and nicotine, which alters pollinator visits, rates of herbivory, and nectar robbery by ants [37]. An even smaller number of studies explicitly link chemically-mediated herbivore and pollinator interactions to plant fitness or focus on communities of insects [38]. However, we are set to see this field grow with flower-feeding herbivores providing particularly tractable models [39]. Indeed, the constraints inherent in chemical pathways may enforce important connections between defence and pollination [40]. It is conceivable that volatile cues under direct selection for pollinator attraction could cause sorting of herbivores across plant chemotypes (Figure 1C illustrates an alternative scenario where there is no correlation between these two traits and no preference-related fitness advantage exists for herbivores).

Alternatively, toxic plant defences can become reliable cues for pollination. Species in the plant genus Bursera (Burseraceae) produce toxic terpenes in their resin, which euglossine bees collect as a reward [41], we propose that defensive and attractive terpenes can potentially trade off through the mevalonate-dependent pathway. Besides playing a fundamental role in flower colouration, flavonoids and anthocyanins are of major importance in plant defences and are both produced through the phenylpropanoid pathway. In morning glory plants [42] and radishes [43] mutations early on in this pathway produce plants with white flowers and no flavonoid based defences. For radishes at least, foliovores prefer unpigmented plants, suggesting a role in defence. Contrastingly, studies on the colour polymorphic Iris lutescens (Iridaceae), which is mainly caused by higher concentration of anthocyanins in purple flowers, found no preference by the florivorous beetle Cetonia hirsuta 
(Coleoptera, Scarabaeidae) on either of the colour morphs [44] Pollinator mediated selection on flower colour also seems to be limited in this Iris species [45].

Outcomes may be determined by the drivers of plant fitness, as well as metabolic constraints. At what stage in the metabolic pathway do changes occur? While small changes in pollinator cues likely lead to host shifts, specialist herbivores can deal with a broad range of structures within a given compound class. Thus, while pollinators may drive compound and bouquet diversity, herbivores may drive structural dissimilarity between related plants. Do we expect patterns of genetic divergence to be similar in all three organisms (plant, herbivores and pollinators)? A pattern of shared fitness landscapes is suggestive of diffuse coevolution. Contrasting correlations between defensive and attractive chemical traits can result in diffuse coevolution between different interactants (Figure 1B). Finally, while beyond the scope of this review, we believe that studying the indirect interactions between pollinators and herbivore communities will yield exciting results. How do pollinator and herbivore communities influence each other's diversity and do metabolic pathways connect them?

\section{Methodological advances}

Advances in genomics such as Restriction site Associated DNA Sequencing (RAD-seq), whole genome scanning, whole genome sequencing (including approaches based on the Illumina 10X technology and the Pac-Bio system) and Genome Wide Association (GWA) are being twinned with methods to test pollinator behaviour and physiological responses such as Gas Chromatography with electroantennographic detection (GC-EAD). This combination will allow routine correlations between Single Nucleotide Polymorphisms (SNP's) and phenotypic traits in linkage disequilibrium, especially in systems amenable to laboratory/greenhouse rearing and crossing. Key developments such as the development of RNA-seq transcriptomics for identifying the candidate genes mediating interactions and regions of the genome harbouring the genes mediating reproductive isolation (so-called 'genomic islands of speciation') [46] (see glossary) will greatly facilitate work aimed at exploring the mechanics of speciation as mediated by chemical diversity for herbivores [4], parasitoids [47] and pollinators. Perhaps more valuable will be the increased focus on studying pollination and herbivory in unison.

\section{Figs and fig wasps: an illustrated example}

One of the best studied obligate pollination mutualisms is that between the $\sim 800$ members of the genus Ficus (Moraceae) and their pollinating wasps (Hymenoptera, Agaonidae) [48,49]. Specialised wasp pollination catalyses high rates of reproductive isolation and speciation in the genus Ficus. A large body of work underlies the conclusion that gravid female wasps are attracted by fig species specific volatile bouquets released at the developmental stage when figs are receptive to pollination [50]. Pollinator speciation is promoted by their relatively short generation time in comparison to figs and evolutionarily labile production of volatile cues [51]. Changes in fig fruit volatile production with development are also responsible for driving the composition of diverse communities of parasitic, or non-pollinating, fig wasps that exploit individual fruit [52].

Similarly, fig trees are part of diffuse food web networks consisting of a diverse community of leaf-eating herbivores. These herbivores may be an equally strong driver of genetic divergence between closely related fig species [31 Volf et al., this issue]. Little is known 
about the influence of herbivory on fig flower chemistry, although connections may exist. It is possible that sequential diversification occurs across figs, pollinators, non-pollinating fig wasps, and leaf-eating herbivores or that leaf-eating herbivores themselves contribute to fig diversification. All these interactions centre around a system in which reproductive costs, leaf defensive traits and insect behaviour are directly measurable, making it an ideal system for studying pathways to cascading speciation both in enclosed wasp communities and defoliating herbivore food webs (Figure 2).

Research has shown that fig volatiles can differ between parapatric populations of figs growing along environmental gradients and among sympatric fig (sub)species. This provides a basis for chemotypic variation and attraction of population specific pollinators $[53,54]$. Gene flow between incipient species and parapatric populations can occur across ecotones but is likely to be mediated by pollinating wasp populations with limited dispersal across climatic gradients. Ensuing speciation should proceed rapidly, especially if key adaptive traits are linked to reproductive traits capable of disrupting the compatibility between both partners (a 'lock and key' mechanism) needed to facilitate reproduction (such as volatile signals in figs or ovipositor length in wasps [54]).

\section{Conclusions and perspectives}

We believe that multiple mechanisms of genetic divergence in insects are mediated by chemical cues and are exemplified by different systems. To some extent these form a continuum along a gradient of specialisation between insects and plants. In systems where the major determinant of plant fitness is seedling establishment and survival to reproductive age, we envisage that specialised insect herbivores can more readily influence evolutionary dynamics than pollinators. This may be the case in the tropical plant genus Piper (Piperaceae) $[55,56]$. Such a model is especially relevant when pollination is through a large community of generalist insects or, indeed, insect-free. In this situation natural variation in plant chemotype becomes a major focus of selection. Here different sets of herbivores can realistically drive divergent selection on plant chemical profile, and in extreme cases even alter the outcome of plant-pollinator dynamics as defensive traits trade off with, for example, nectar quality or pollinator attraction [57-59]. We suggest that specialised pollinators are perhaps more likely than specialised herbivores to lead to divergent selection, as gene flow is more directly limited if pollinator preference evolves (Figure 1C). Here the major determinant of plant fitness is seed set and pollination efficiency, and this model may be more relevant for low density and herbivore-poor systems, such as orchids. It is conceivable that selection on volatile attractants can even feed back to alter insect herbivore communities in the same way as for other floral traits [60], especially in flower-feeding insects [61]. In most situations pollinators and herbivores both contribute to intra-specific divergence in plants and specific outcomes depend more on the exact context. Figs, their wasps and their herbivores likely sit between the middle and left panels in Figure 1. These will be the cases where pleiotropy between genes relevant for defensive and pollinator traits matters and such systems offer the greatest potential focus for future research.

\section{Declarations of interest: none}




\section{Acknowledgements}

STS, MS and DSC were funded by GACR grant 15-24571S. MV acknowledges funding by Alexander von Humboldt Foundation and the Federal Ministry for Education and Research. We acknowledge Mike Singer and an anonymous reviewer for constructive criticism of an earlier version of this manuscript. 


\section{References}

1. Singer MS, Stireman JO: The tri-trophic niche concept and adaptive radiation of phytophagous insects. Ecol Lett 2005, 8:1247-1255.

2. Clare EL, Schiestl FP, Leitch AR, Chittka L: The promise of genomics in the study of plantpollinator interactions. Genome Biol 2013, 14:207.

3. Anderson JT, Mitchell-Olds T: Ecological genetics and genomics of plant defences: evidence and approaches: Ecogenomics of plant defence. Funct Ecol 2011, 25:312-324.

4. Simon J-C, d'Alencon E, Guy E, Jacquin-Joly E, Jaquiery J, Nouhaud P, Peccoud J, Sugio A, Streiff R: Genomics of adaptation to host-plants in herbivorous insects. Brief Funct Genomic 2015, 14:413-423.

5. Agosta SJ: On ecological fitting, plant-insect associations, herbivore host shifts, and host plant selection. Oikos 2006, 114:556-565.

6. Jabis MD, Ayers TJ, Allan GJ: Pollinator-mediated gene flow fosters genetic variability in a narrow alpine endemic, Abronia alpina (Nyctaginaceae). Am J Bot 2011, 98:1583-1594.

7. Reis TS, Ciampi-Guillardi M, Bajay MM, de Souza AP, dos Santos FAM: Elevation as a barrier: genetic structure for an Atlantic rain forest tree (Bathysa australis) in the Serra do Mar mountain range, SE Brazil. Ecol Evol 2015, 5:1919-1931.

8. Gervasi DDL, Schiestl FP: Real-time divergent evolution in plants driven by pollinators. Nat Commun 2017, 8:14691.

9. van der Niet T, Peakall R, Johnson SD: Pollinator-driven ecological speciation in plants: new evidence and future perspectives. Ann Bot 2014, 113:199-212.

10. Downey MH, Nice CC: Experimental evidence of host race formation in Mitoura butterflies (Lepidoptera: Lycaenidae). Oikos 2011, 120:1165-1174.

11. Forbes AA, Devine SN, Hippee AC, Tvedte ES, Ward AKG, Widmayer HA, Wilson CJ: Revisiting the particular role of host shifts in initiating insect speciation: perspective. Evolution 2017, 71:1126-1137.

12. Hood GR, Forbes AA, Powell THQ, Egan SP, Hamerlinck G, Smith JJ, Feder JL: Sequential divergence and the multiplicative origin of community diversity. Proc Natl Acad Sci USA 2015, 112:E5980-E5989.

13. Stireman JO, Nason JD, Heard SB, Seehawer JM: Cascading host-associated genetic differentiation in parasitoids of phytophagous insects. Proc Royal Soc B 2006, 273:523-530.

14. Ehrlich PR, Raven PH: Butterflies and plants: a study in coevolution. Evolution 1964, 18:586608.

15. Janz N, Nylin S: The oscillation hypothesis of host-plant range and speciation. In Specialization, speciation, and radiation: the evolutionary biology of herbivorous insects. Edited by Tilmon KJ. University of California Press; 2008:203-215. 
16. Bengtsson M, Boutitie A, Josvai J, Toth $M$, Andreadis $S$, Rauscher $S$, Unelius CR, Witzgall P: Pheromone races of Cydia splendana (Lepidoptera, Tortricidae) overlap in host plant association and geographic distribution. Front Ecol Evol 2014, 2.

17. Bruce TJA, Wadhams $L$, Woodcock CM: Insect host location: a volatile situation. Trends Plant Sci 2005, 10:269-274.

18. Reddy GV., Guerrero A: Interactions of insect pheromones and plant semiochemicals. Trends Plant Sci 2004, 9:253-261.

19. Smadja C, Butlin RK: On the scent of speciation: the chemosensory system and its role in premating isolation. Heredity 2009, 102:77-97.

20. Borrero-Echeverry F, Bengtsson M, Nakamuta K, Witzgall P: Plant odor and sex pheromone are integral elements of specific mate recognition in an insect herbivore. Evolution 2018, 72:2225-2233.

21. Fatouros NE, Dicke M, Mumm R, Meiners T, Hilker M: Foraging behavior of egg parasitoids exploiting chemical information. Behav Ecol 2008, 19:677-689.

22. Vet LEM, Dicke M: Ecology of infochemical use by natural enemies in a tritrophic context. Annu Rev Entomol 1992, 37:141-172.

23. Fors L, Mozuraitis R, Blažytè-Čereškienè L, Verschut TA, Hambäck PA: Selection by parasitoid females among closely related hosts based on volatiles: Identifying relevant chemical cues. Ecol Evol 2018, 8:3219-3228.

24. Konig K, Krimmer E, Brose S, Gantert C, Buschluter I, Konig C, Klopfstein S, Wendt I, Baur H, Krogmann $L$, et al.: Does early learning drive ecological divergence during speciation processes in parasitoid wasps? Proc Royal Soc B 2014, 282:20141850-20141850.

25. Goldman-Huertas B, Mitchell RF, Lapoint RT, Faucher CP, Hildebrand JG, Whiteman NK: Evolution of herbivory in Drosophilidae linked to loss of behaviors, antennal responses, odorant receptors, and ancestral diet. Proc Natl Acad Sci USA 2015, 112:3026-3031.

26. Adler LS: Alkaloid uptake increases fitness in a hemiparasitic plant via reduced herbivory and increased pollination. Am Nat 2000, 156:92-99.

27. Kessler A, Halitschke R: Testing the potential for conflicting selection on floral chemical traits by pollinators and herbivores: predictions and case study. Funct Ecol 2009, 23:901-912.

28. Armbruster WS: Floral specialization and angiosperm diversity: phenotypic divergence, fitness trade-offs and realized pollination accuracy. AoB PLANTS 2014, 6.

29. Whitehead MR, Peakall R: Integrating floral scent, pollination ecology and population genetics. Funct Ecol 2009, 23:863-874.

30. Adler LS, Seifert MG, Wink M, Morse GE: Reliance on pollinators predicts defensive chemistry across tobacco species. Ecol Lett 2012, 15:1140-1148.

31. Volf M, Segar ST, Miller SE, Isua B, Sisol M, Aubona G, Simek P, Moos M, Laitila J, Kim J, et al.: Community structure of insect herbivores is driven by conservatism, escalation and divergence of defensive traits in Ficus. Ecol Lett 2018, 21:83-92. 
32. Agrawal AA, Fishbein M: Phylogenetic escalation and decline of plant defense strategies. Proc Natl Acad Sci USA 2008, 105:10057-10060.

33. Volf M, Julkunen-Tiitto R, Hrcek J, Novotny V: Insect herbivores drive the loss of unique chemical defense in willows. Entomol Exp Appl 2015, 156:88-98.

34. Strauss SY, Irwin RE: Ecological and evolutionary consequences of multispecies plant-animal interactions. Annu Rev Ecol Evol Syst 2004, 3:435-466.

35. Nunes CEP, Peñaflor MFGV, Bento JMS, Salvador MJ, Sazima M: The dilemma of being a fragrant flower: the major floral volatile attracts pollinators and florivores in the euglossinepollinated orchid Dichaea pendula. Oecologia 2016, 182:933-946.

36. Sauve AMC, Thébault E, Pocock MJO, Fontaine C: How plants connect pollination and herbivory networks and their contribution to community stability. Ecology 2015, doi:10.1890/15-0132.1.

37. Kessler D, Gase K, Baldwin IT: Field experiments with transformed plants reveal the sense of floral scents. Science 2008, 321:1200-1202.

38. Rusman Q, Lucas-Barbosa D, Poelman EH: Dealing with mutualists and antagonists: Specificity of plant-mediated interactions between herbivores and flower visitors, and consequences for plant fitness. Funct Ecol 2018, 32:1022-1035.

39. Li R, Schuman MC, Wang Y, Llorca LC, Bing J, Bennion A, Halitschke R, Baldwin IT: Jasmonate signaling makes flowers attractive to pollinators and repellant to florivores in nature: JA regulates floral display and defense in nature. J Integr Plant Biol 2018, 60:190-194.

40. Dyer LA, Philbin CS, Ochsenrider KM, Richards LA, Massad TJ, Smilanich AM, Forister ML, Parchman TL, Galland LM, Hurtado PJ, et al.: Modern approaches to study plant-insect interactions in chemical ecology. Nat Rev Chem 2018, 2:50-64.

41. Armbruster WS: The role of resin in angiosperm pollination: ecological and chemical considerations. Am J Bot 1984, 71:1149-1160.

42. Fineblum WL, Rausher MD: Do floral pigmentation genes also influence resistance to enemies? The $W$ locus in Ipomoea purpurea. Ecology 1997, 78:1646-1654.

43. McCall AC, Murphey SJ, Venner C, Brown M: Florivores prefer white versus pink petal color morphs in wild radish, Raphanus sativus. Oecologia 2013, 172:189-195.

44. Imbert E, Wang H, Anderson B, Hervouet B, Talavera M, Schatz B: Reproductive biology and colour polymorphism in the food-deceptive Iris lutescens (Iridaceae). Acta Botanica Gallica 2014, 161:117-127.

45. Souto-Vilarós D, Vuleta A, Manitasevic S, Wang H, Sapir Y, Imbert E: Are pollinators the agents of selection on flower colour and size in irises? Oikos 2018, 127:834-846.

46. Butlin RK: Population genomics and speciation. Genetica 2010, 138:409-418.

47. Lindsey ARI, Kelkar YD, Wu X, Sun D, Martinson EO, Yan Z, Rugman-Jones PF, Hughes DST, Murali SC, Qu J, et al.: Comparative genomics of the miniature wasp and pest control agent Trichogramma pretiosum. BMC Biology 2018, 16. 
48. Cook JM, Rasplus J-Y: Mutualists with attitude: coevolving fig wasps and figs. Trends Ecol Evol 2003, 18:241-248.

49. Cook JM, Segar ST: Speciation in fig wasps. Ecol Entomol 2010, 35:54-66.

50. Hossaert-McKey M, Soler C, Schatz B, Proffit M: Floral scents: their roles in nursery pollination mutualisms. Chemoecology 2010, 20:75-88.

51. Moe AM, Clement W, Weiblen GD: Rapid evolution of pollinator-mediated plant reproductive isolation. In Rapidly Evolving Genes and Genetic Systems. Edited by Singh RS, Jianping X, Kulathinal R. Oxford University Press; 2012:312.

52. Proffit $M$, Schatz B, Borges R, Hossaert-Mckey M: Chemical mediation and niche partitioning in nonpollinating fig-wasp communities. J Anim Ecol 2007, 76:293-303.

53. Wang $\mathrm{G}$, Cannon $\mathrm{CH}$, Chen J: Pollinator sharing and gene flow among closely related sympatric dioecious fig taxa. Proc Royal Soc B 2016, 283:20152963.

54. Souto-Vilarós D, Proffit M, Buatois B, Rindos M, Sisol M, Kuyaiva T, Isua B, Michalek J, Darwell $\mathrm{CT}$, Hossaert-McKey $\mathrm{M}$, et al.: Pollination along an elevational gradient mediated both by floral scent and pollinator compatibility in the fig and fig-wasp mutualism. J Ecol 2018, doi:10.1111/1365-2745.12995.

55. Richards LA, Dyer LA, Forister ML, Smilanich MA, Dodson CD, Leonard MD, Jefferey CS: Phytochemical diversity drives plant-insect community diversity. Proc Natl Acad Sci USA 2015, 112:10973-10978.

56. Glassmire AE, Jeffrey CS, Forister ML, Parchman TL, Nice CC, Jahner JP, Wilson JS, Walla TR, Richards LA, Smilanich AM, et al.: Intraspecific phytochemical variation shapes community and population structure for specialist caterpillars. New Phytol 2016, 212:208-219.

57. Adler LS, Wink $M$, Distl $M$, Lentz AJ: Leaf herbivory and nutrients increase nectar alkaloids. Ecol Lett 2006, 9:960-967.

58. Manson JS, Rasmann S, Halitschke R, Thomson JD, Agrawal AA: Cardenolides in nectar may be more than a consequence of allocation to other plant parts: a phylogenetic study of Asclepias. Funct Ecol 2012, 26:1100-1110.

59. Glaum $\mathrm{P}$, Kessler A: Functional reduction in pollination through herbivore-induced pollinator limitation and its potential in mutualist communities. Nat Commun 2017, 8.

60. Kessler D, Kallenbach M, Diezel C, Rothe E, Murdock M, Baldwin IT: How scent and nectar influence floral antagonists and mutualists. eLife 2015, 4.

61. Strauss SY, Conner JK, Rush SL: Foliar herbivory affects floral characters and plant attractiveness to pollinators: implications for male and female plant fitness. Am Nat 1996, 147:1098-1107.

62. Quicke D, Smith MA, Hrcek J, Butcher B: Cystomastacoides van Achterberg (Braconidae, Rogadinae): first host record and descriptions of three new species from Thailand and Papua New Guinea. J Hymenopt Res 2013, 31:65-78. 


\section{Diehl SR, Bush GL: An evolutionary and applied perspective of insect biotypes. Annu Rev Entomol 1984, 29:471-504.}

\section{Annotated papers}

- Special interest

Gervasi DDL, Schiestl FP: Real-time divergent evolution in plants driven by pollinators. Nature Communications 2017, 8:14691.

A rare real time example of adaptive divergence in Brassica as mediated by two groups of pollinators. Directly demonstrating that different types (in this case bumblebees and hover flies) of pollinators can select for divergent floral traits is highly relevant because it quantifies the speed at which these changes can happen.

Rusman Q, Lucas-Barbosa D, Poelman EH: Dealing with mutualists and antagonists: Specificity of plant-mediated interactions between herbivores and flower visitors, and consequences for plant fitness. Functional Ecology 2018, 32:1022-1035.

Another study to use a Brassica model, these authors quantify the influence that a range of herbivore guilds have on host plant pollinator visitation and fitness. The results show that individual herbivore species and entire guilds have consistent indirect effects on plant reproduction and pollinator community structure and demonstrate the strong linkage between these two webs.

Fors L, Mozuraitis R, Blažytė-Čereškienė L, Verschut TA, Hambäck PA: Selection by parasitoid females among closely related hosts based on volatiles: Identifying relevant chemical cues. Ecology and Evolution 2018, 8:3219-3228.

Fors et al. also test the hypothesis that oviposition site and chemical cues are inter-connected and demonstrate that earlier life stages can influence female choice through a 'chemical legacy'. In combination with host insect specificity this kind of link may reinforce assortative mating and genetic divergence. An excellent integrative study using behavioural and chemical approaches to assess the ability of parasitoids to detect resistant and non-resistant hosts.

Souto-Vilarós D, Proffit M, Buatois B, Rindos M, Sisol M, Kuyaiva T, Isua B, Michalek J, Darwell CT, Hossaert-McKey M, et al.: Pollination along an elevational gradient mediated both by floral scent and pollinator compatibility in the fig and fig-wasp mutualism. Journal of Ecology 2018, doi:10.1111/1365-2745.12995.

With a focus on pollinator behaviour and volatile emissions this study examines the proximate mechanisms maintaining the putative reproductive isolation of lowland/highland pairs of fig species. The study suggests that chemical cues, pollinator behaviour and pollinator morphology act in unison to maintain reproductive barriers in this system.

Endara M-J, Coley PD, Ghabash G, Nicholls JA, Dexter KG, Donoso DA, Stone GN, Pennington RT, Kursar TA: Coevolutionary arms race versus host defense chase in a tropical herbivore-plant system. Proc Natl Acad Sci USA 2017, 114:E7499-E7505. 
A detailed study of the tropical plant genus Inga incorporating bipartite phylogenies (of both plants and herbivores) and a plethora of chemical data. Plant defences are shown to drive the distribution of insect herbivores across plants, plant defences themselves are largely independent of phylogeny in this genus.

•• Outstanding interest

Kagiya S, Yasugi M, Kudoh H, Nagano AJ, Utsumi S: Does genomic variation in a foundation species predict arthropod community structure in a riparian forest? Molecular Ecology 2018, 27:1284-1295.

Intra-specific genetic variation is the raw material upon which selection acts. A basic assumption of cascading divergence is that genotypes within a species vary with respect to plant traits mediating herbivore host use. This assumption is held in a population of 85 mature alder (Alnus) trees in a Japanese forest.

\section{Glossary}

Host race. Diehl and Bush [63] define an insect host race as "a population of an [insect] species that is partially reproductively isolated from other conspecific populations as a direct consequence of adaptation to a specific host".

Ecological fitting. Agosta et al. [5] define ecological fitting as "the process whereby organisms colonize and persist in novel environments, use novel resources or form novel associations with other species as a result of the suites of traits that they carry at the time they encounter the novel condition."

Genomic islands of speciation. Regions of the genome harbouring the genes responsible for reproductive isolation, they are resistant to homogenisation by gene flow.

Split and sort speciation. A model for fig wasp speciation based partly on the observations that i) there are many more pollinating fig-wasps than figs and ii) that there is a large discrepancy between fig and wasp generation times. Cook and Segar [49] proposed that a single speciation event in figs could yield two new pollinator species (a split). Speciation in wasps, but not figs, leads to multiple pollinators associated with a single (or even multiple) fig species. In older lineages of figs extinction and species sorting can give the impression of one-to-one interactions. 


\section{Figures}

Figure 1. Multiple outcomes of chemically-mediated limitations to gene flow in herbivores and pollinators on plants. In all cases, plant, herbivore and pollinator fitness are plotted against genetically determined plant trait values, or insect preference. Arrows on each plot indicate the expected strength of gene flow between each genotype. Outcomes are dependent on selection imposed predominantly by specialist herbivores (panel A) or specialist pollinators (panel C). Panel A emphasises the role of chemical defences and specialized herbivorous insects; here intra-specific variation in plant defences leads to local adaptation by herbivores (host races) (see glossary). Plant fitness is determined by the ability of genotypes with alternative chemistry to establish and survive. Herbivore fitness is dependent on the insect's ability to adapt to host genotypes. Parasitoids can act to reinforce diversification in herbivores through facilitating variation in enemy free space [1] or themselves segregate over herbivore populations [12]. In this case, pollinator fitness remains constant across plant genotypes unless changes in defensive traits correlate with volatile cues or nectar quality. Gene flow barriers may arise if individuals with intermediate trait values suffer from extreme outbreeding depression. Panel $\mathrm{C}$ illustrates the case where pollination success is a greater determinant of plant fitness than survival to reproductive age. Here, selection against individuals with intermediate pollination cues will lead to formation of distinct plant populations, each with their own pollinators (see model of 29). How herbivores respond is dependent on the palatability and frequency of each genotype, here there is no fitness cost for preferring either plant genotype. In most cases, however, plant fitness will be determined by both the need to maintain reproductive fidelity and repel insect herbivores (Panel B). In panel B we consider a situation where chemical leaf defences and pollination cues are correlated, such that better defended plants tend to produce more attractive volatiles. Plant and pollinator fitness are linked, and herbivores should prefer less well defended plants. The interactions between pollinators and herbivores as mediated by plant chemistry can have dramatic results across these two webs [38]. We expect that plant defensive traits more commonly determine pollinator behaviour than pollination related cues do herbivores. Note that directional trends in chemical diversity (e.g. escalation) are not considered in this simplified set of models. 


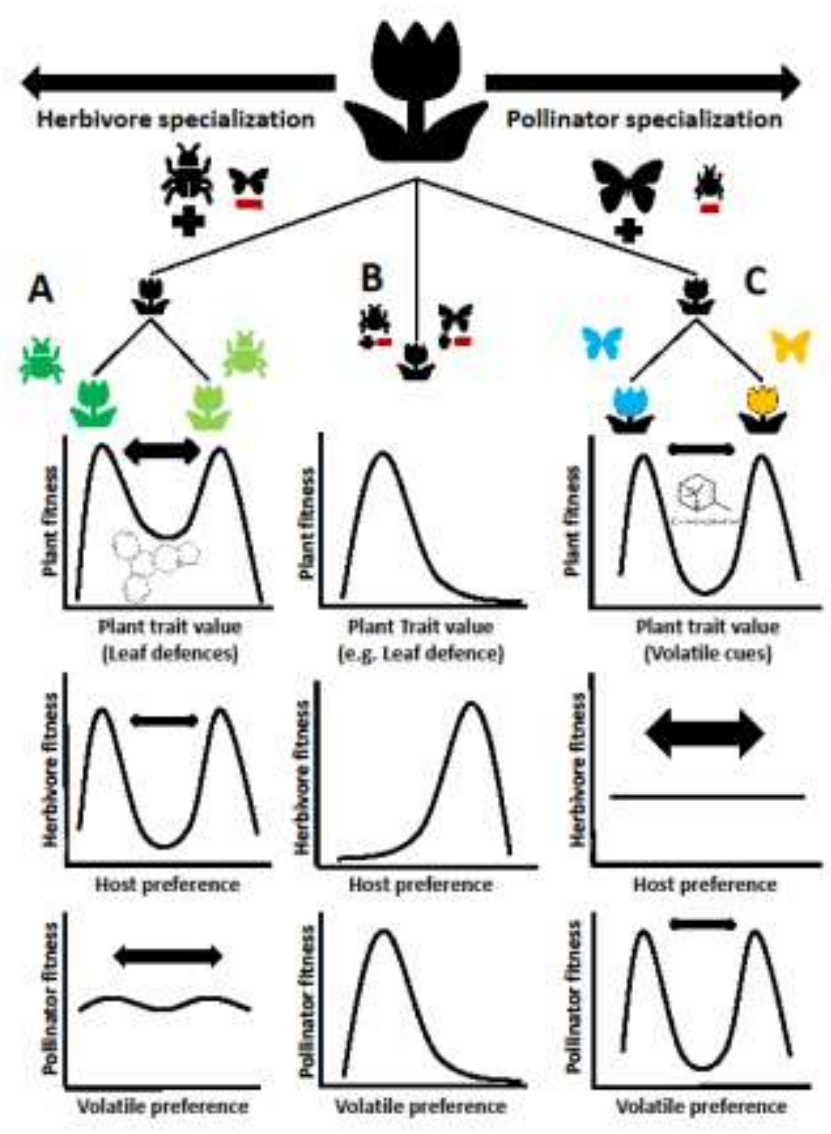

Figure 2. Hypothesised chemically-mediated genetic divergence in fig mutualists and antagonists (based on real examples from references 31 and 54) and across different time scales. Panel A illustrates differences in chemical composition (in this case alkaloids) associated with genetically distinct insect herbivores (specialist moths from the erebid genus Asota (Lepidoptera, Erebidae) that likely sequester alkaloids) and, putatively, different parasitoids (e.g. Cystomastacoides asotaphaga (Hymenoptera, Braconidae) [62]). This host associated divergence can fuel larger adaptive radiations of herbivores and parasites (panel B). Panel C illustrates the patterns that we expect to emerge if different fig volatile bouquets can potentially mediate pollinator behaviour, reinforce genetic boundaries in figs and trigger cascading diversification in parasitoid populations (in this case the two morphs of Sycoscapter (Hymenoptera, Pteromalidae) parasitoid both exploit one pollinator in sympatry). This process would follow the 'sequential diversification' model [12]. Fig divergence can be ecologically mediated or occur in allopatry. Wasps have much shorter generation times than figs, leading to higher rates of speciation and several wasp species per fig through 'split and sort' speciation [49]. Panel D illustrates one expected macroevolutionary outcome of these dynamics across each trophic level. Chemical diversity and specificity in chemically-mediated interactions are at the heart of speciation in both herbivore and pollinator networks and comparative studies have great potential for exploring correlations between the traits mediating insect behaviour. 


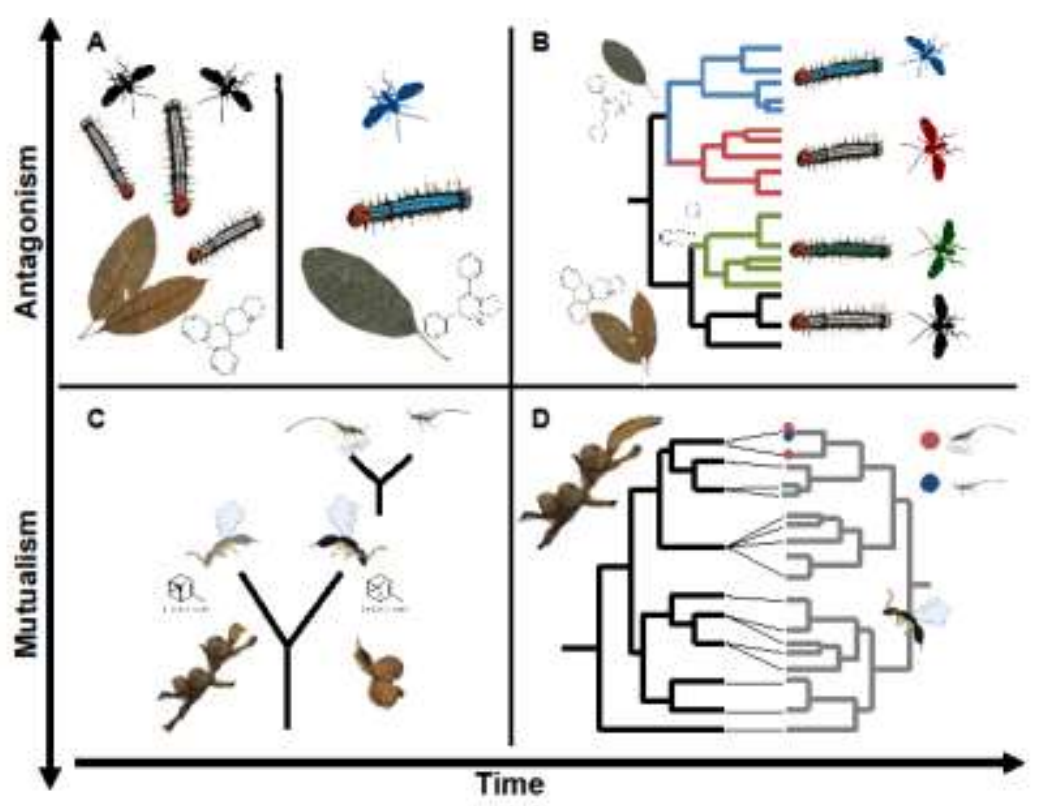

